\title{
The aryl hydrocarbon receptor repressor is a putative tumor suppressor gene in multiple human cancers
}

\author{
Enrique Zudaire, ${ }^{1}$ Natalia Cuesta, ${ }^{2}$ Vundavalli Murty, ${ }^{3}$ Karen Woodson, ${ }^{4}$ Lisa Adams, ${ }^{4}$ \\ Nieves Gonzalez, ${ }^{5}$ Alfredo Martínez, ${ }^{6}$ Gopeshwar Narayan, ${ }^{3}$ Ilan Kirsch, ${ }^{7}$ Wilbur Franklin, ${ }^{8}$ \\ Fred Hirsch, ${ }^{8}$ Michael Birrer, ${ }^{7}$ and Frank Cuttitta ${ }^{1}$
}

\begin{abstract}
${ }^{1}$ Angiogenesis Core Facility, NCI, NIH, Gaithersburg, Maryland, USA. ${ }^{2}$ Department of Microbiology and Immunology, University of Maryland, Baltimore, Maryland, USA. ${ }^{3}$ Department of Pathology, College of Physicians and Surgeons, Columbia University, New York, New York, USA. ${ }^{4}$ Genetics Branch, NCI, and ${ }^{5}$ NIDDK, NIH, Bethesda, Maryland, USA. ${ }^{6}$ Department of Neuroanatomy and Cell Biology, Instituto Cajal, Consejo Superior de Investigaciones Científicas, Madrid, Spain. ${ }^{7}$ Center for Cancer Research, NCI, NIH, Bethesda, Maryland, USA. ${ }^{8}$ University of Colorado Cancer Center, Aurora, Colorado, USA.
\end{abstract}

The aryl hydrocarbon receptor repressor (AHRR) is a bHLH/Per-ARNT-Sim transcription factor located in a region of chromosome 5 ( $5 \mathrm{p} 15.3)$ that has been proposed to contain one or more tumor suppressor genes. We report here consistent downregulation of $A H R R$ mRNA in human malignant tissue from different anatomical origins, including colon, breast, lung, stomach, cervix, and ovary, and demonstrate DNA hypermethylation as the regulatory mechanism of $A H R R$ gene silencing. Knockdown of $A H R R$ gene expression in a human lung cancer cell line using siRNA significantly enhanced in vitro anchorage-dependent and -independent cell growth as well as cell growth after transplantation into immunocompromised mice. In addition, knockdown of $A H R R$ in non-clonable normal human mammary epithelial cells enabled them to grow in an anchorage-independent manner. Further, downregulation of AHRR expression in the human lung cancer cell line conferred resistance to apoptotic signals and enhanced motility and invasion in vitro and angiogenic potential in vivo. Ectopic expression of $A H R R$ in tumor cells resulted in diminished anchorage-dependent and -independent cell growth and reduced angiogenic potential. These results therefore demonstrate that AHRR is a putative new tumor suppressor gene in multiple types of human cancers.

\section{Introduction}

The aryl hydrocarbon receptor repressor $(A H R R)$ is a newly discovered member of the growing superfamily of basic helix-loophelix/Per-ARNT-Sim (bHLH/Per-ARNT-Sim) transcription factors, which includes the aryl hydrocarbon receptor $(A H R)(1)$ and hypoxia inducible factor 1 (HIF1) (2), among others. AHRR represses the transcription activity of AHR by competing with this transcription factor for heterodimer formation with the AHR nuclear translocator (ARNT) (3) and subsequently binding to the xenobiotic response element (XRE) sequence (4), functioning as a naturally occurring dominant-negative factor. Furthermore, the expression of AHRR is induced by the AHR/ARNT heterodimer (5) through binding to XREs located in the $5^{\prime}$-flanking region of the AHRR gene. Therefore, AHRR and AHR constitute a regulatory loop in which the heterodimer AHR/ARNT activates expression of the AHRR gene, while the expressed AHRR inhibits the function of AHR (4).

Proof of the role of AHR as a ligand-activated transcription factor that mediates a pleiotropic response to environmental contaminants, such as benzo[a]pyrene, 2,3,7,8-tetrachlorodibenzo-pdioxin, and tobacco smoke is extensive $(6,7)$. More importantly, data exist implicating AHR in the development of cancers from different anatomical origins (8-10). Compelling evidence of the

Nonstandard abbreviations used: AHR, aryl hydrocarbon receptor; AHRR, AHR repressor; ARNT, AHR nuclear translocator; bHLH, basic helix-loop-helix; FAK, focal adhesion kinase; LOH, loss of heterozygosity; NCI, National Cancer Institute; RPMI-10, RPMI supplemented with 10\% FBS; XRE, xenobiotic response element. Conflict of interest: The authors have declared that no conflict of interest exists. Citation for this article: J. Clin. Invest. 118:640-650 (2008). doi:10.1172/JCI30024. tumorigenic potential of $A H R$ comes from the fact that $A H R$ overexpressing transgenic mice spontaneously develop tumors $(8,9)$, whereas $A H R$-knockout mice have increased resistance to carcinogens (11). In this context, as an $A H R$ regulator, $A H R R$ is potentially involved in a vast array of normal and pathological processes ranging from xenobiotic response to tumor progression. In humans, AHRR maps to the short arm of chromosome 5 ( $5 \mathrm{p} 15)$. This chromosomal region has been shown to be frequently deleted in a variety of tumor types, such as cervical and testicular germ tumors (12), colorectal cancer (13), early-stage ovarian tumors (14), bladder cancer (15), esophageal cancer (16), and lung tumors (17). Based on these loss-of-heterozygosity (LOH) studies, 5 p 15 has been often proposed as a chromosomal locus which likely harbors at least one tumor suppressor gene. The role of AHRR in carcinogenesis has not been extensively explored. Overexpression of AHRR in the breast cancer cell line MCF-7 results in growth inhibition (18) and genetic polymorphisms in AHRR are related to susceptibility to advanced endometriosis (19). Here we provide clinical, genetic, and functional evidence from in vitro and in vivo experiments supporting a critical role of $A H R R$ as a putative tumor suppressor gene in several types of human cancer.

\section{Results}

AHRR is downregulated in tumor cells. Our results show a consistent downregulation of $A H R R$ throughout all the tumor types assessed in this study, including colon, breast, lung, stomach, cervical, and ovarian, when compared with normal tissues of the same anatomical origin (Figure 1). In preliminary experiments lung, breast, stomach, and colon primary tumors showed substantial downregula- 


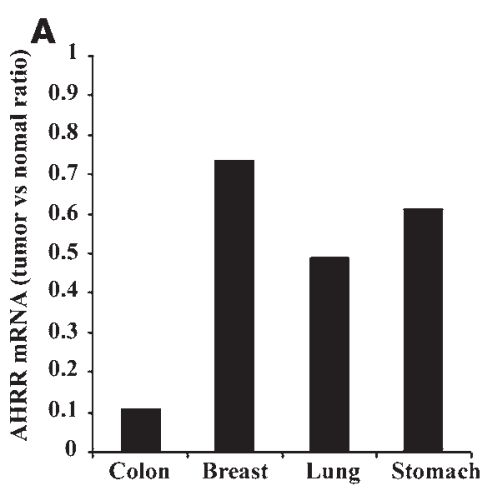

B
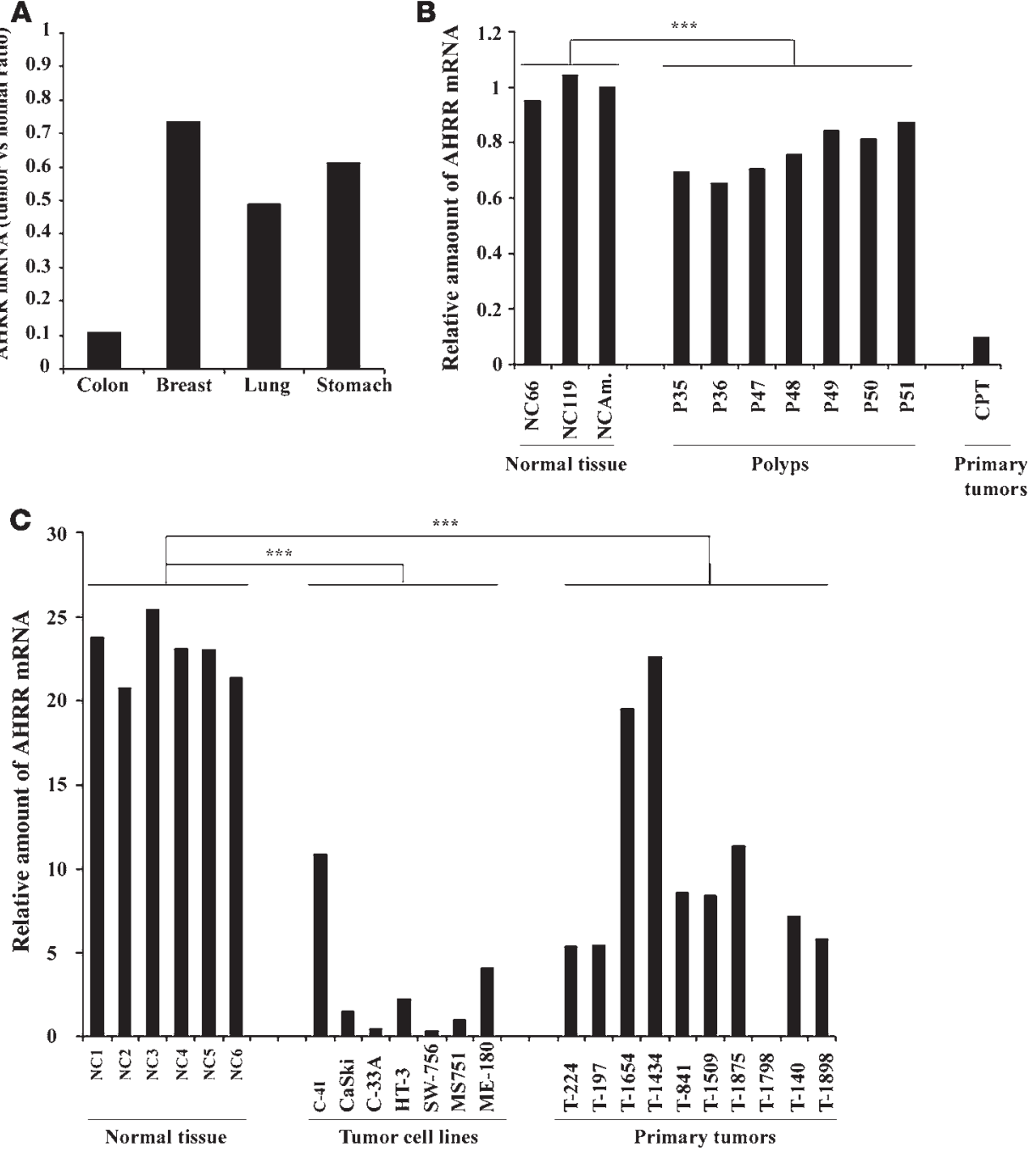

Figure 1

AHRR mRNA expression levels in tumors and normal controls as assessed by real-time PCR. (A) Significant downregulation in $A H R R$ mRNA (between $30 \%$ and $90 \%$ ) was observed in tumors from several origins. Data are presented as a ratio of mRNA levels in tumor versus normal control. (B) Primary colon tumors showed a very strong downregulation of AHRR mRNA when compared with normal controls. Interestingly, nonmalignant colon polyps exhibited a more moderate downregulation of AHRR mRNA when compared with colon tumors. Statistically significant differences were achieved when comparing levels of $A H R R$ in normal tissue with levels in polyps. (C) AHRR expression levels in normal cervical tissue, cervical tumor cell lines, and primary cervical tumors. Strong downregulation or complete ablation of $A H R R$ mRNA was observed in $100 \%$ of cell lines and $80 \%$ of the primary tumors when compared with normal controls. Little variation was observed in the levels of AHRR mRNA among the normal controls. (D) All ovarian tumor cell lines included in this study showed downregulation of $A H R R$ mRNA levels when compared with normal ovarian cell lines. (E) Boxand-whisker plot showing significant downregulation AHRR mRNA levels observed in lung tumors and normal tissues from the same patients. ${ }^{\star \star \star} P<0.001$.

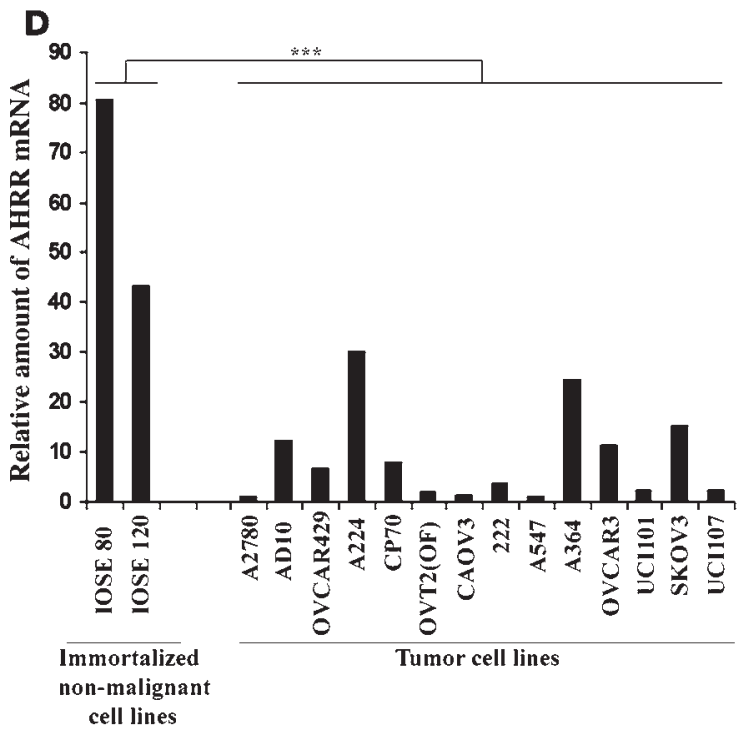

E

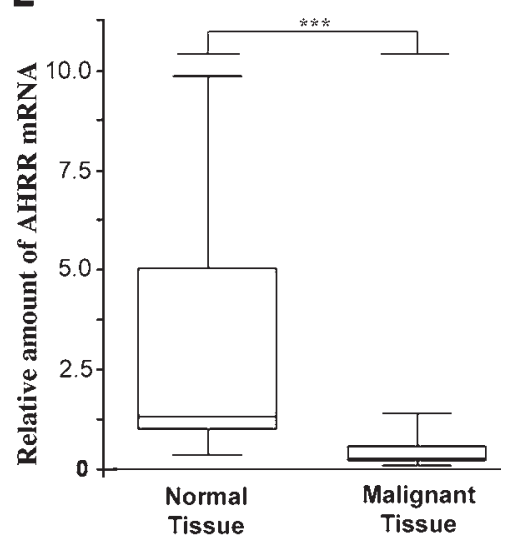

tion of AHRR when compared with normal tissue from the same patient, adjacent to the tumor (Figure 1A). Interestingly, some of the hyperplastic or adenomatous nonmalignant colon polyps showed a smaller (up to 40\%) downregulation of AHRR (Figure 1B), suggesting a direct relationship between levels of $A H R R$ expression and degree of transformation in colon cancer. In a separate experi- 
Table 1

AHRR promoter hypermethylation in cancer

\begin{tabular}{lcccc} 
Tumor type & No. studied & Methylated (\%) & UM/M (\%) & M/M (\%) \\
Normal testis & 4 & 0 & 0 & 0 \\
Testicular cancer & 79 & 44.3 & 42.8 & 57.2 \\
$\quad$ Seminoma & 15 & 13.3 & 50 & 50 \\
$\quad$ Nonseminoma & 64 & 51.6 & 42.4 & 57.6 \\
Normal cervix & 44 & 0 & 0 & 0 \\
Cervical cancer & 66 & 95.5 & 81 & 19 \\
$\quad$ Cell lines & 9 & 100 & 11.1 & 88.9 \\
$\quad$ Primary tumors & 57 & 94.7 & 92.6 & 7.4 \\
Precancer & & & & \\
$\quad$ Low-grade & 48 & 4.2 & ND & ND \\
$\quad$ High-grade & 39 & 41 & ND & ND \\
Normal ovary & 2 & 0 & 0 & 0 \\
Ovarian cancer & 14 & 100 & 21.4 & 78.6 \\
Prostate cancer & 6 & 67 & ND & ND \\
Colon cancer & 8 & 100 & ND & ND \\
Normal esophagus & 8 & 0 & ND & ND \\
Low-grade dysplasia & 8 & 0 & ND & ND \\
High-grade dysplasia & 7 & 28 & ND & ND \\
Tumor & 23 & 52 & ND & ND \\
\hline
\end{tabular}

M/M, only methylated allele present; UM/M, unmethylated and methylated alleles present; ND, not done. that seminomatous germ cell tumors rarely exhibit promoter hypermethylation; ref. 22). Interestingly, levels of promoter hypermethylation were closely correlated with cancer grade in cervical and esophageal specimens: low-grade precancerous lesions showed the lowest levels of promoter methylation (4.2\% and $0 \%$, respectively), higher levels were observed in high-grade lesions ( $41 \%$ and $28 \%$, respectively), and virtually all established cervical tumors (95.5\%) and $52 \%$ of esophageal tumors were methylated. Further supporting evidence that hypermethylation is a main regulatory mechanism of $A H R R$ silencing in tumors comes from experiments in which tumor cells are exposed to demethylating agents. Treatment of tumor cells with 5-aza-dC and/or trichostatin A significantly reactivated $A H R R$ expression (more than 1.5 -fold increase) in $71.5 \%$ of the tumor cell lines included in the experiment (Supplemental Table 3). These data thus show that epigenetic alterations (i.e., hypermethylation) are largely responsible for downregulation of $A H R R$ in cancer cells. Analysis of the 5' regulatory region of $A H R R$ showed several binding motif sites were found in the same region affected by hypermethylation including AP-2, c-Est-1, and Elk-1 (Supplemental Table 4). Especially interesting was a short sequence, located close to the star codon ( -55 to $-41 \mathrm{bp}$ from the start codon), which contained

ment, we found that $80 \%$ of cervical primary tumors and $100 \%$ of cervical cell lines showed significant reduction or complete abrogation of AHRR when compared with normal tissue (Figure 1C). Similar results were obtained with 14 ovarian carcinoma cell lines examined, which showed a strong downregulation of $A H R R$ when compared with immortalized nonmalignant ovarian cell lines (Figure 1D). Additional proof of downregulation of AHRR mRNA in cancer comes from comparison of 11 lung tumor samples and normal tissue from the same patients (Figure 1E). All tumor samples showed significant silencing of AHRR mRNA when compared with their normal counterparts. Overall, these results show a consistent downregulation of AHRR mRNA in tumors of different histological origins (Supplemental data; supplemental material available online with this article; doi:10.1172/JCI30024DS1).

AHRR satisfies Knudson's "2-hit" bypothesis. Because of the downregulated expression of the AHRR gene in tumors from different tissue origins, and the frequent $\mathrm{LOH}$ at the $5 \mathrm{p} 15$ chromosomal region (12), we reasoned that $A H R R$ might be a potential tumor suppressor gene. Knudson's “two hits” hypothesis considers tumor suppressor genes by their functional inactivation achieved by a combination of $\mathrm{LOH}$, hypermethylation of the gene's promoter, and mutations in the gene's coding region (20). Although, as expected from previous studies $(12,21)$, a number of polymorphisms and evidence for frequent $\mathrm{LOH}$ of this region was obtained in this study (Supplemental Table 2), no evidence of pathogenic mutations in the coding region of the AHRR gene was found, pointing to hypermethylation as a possible mechanism responsible for its steady downregulation in tumors. Promoter hypermethylation was found in over $78 \%$ of the tumors examined (Table 1 and Supplemental Figure 2), while no methylation was found in normal tissue. Remarkably, almost all ovarian, cervical, and colon tumors exhibited promoter hypermethylation. The lowest hypermethylation rate (13\%) was found in seminoma testicular tumors (it has been reported potential binding sites for several members of the bHLH family of transcription factors including AHR and HIF.

The collective data shown above strongly suggest that $A H R R$ may function as a tumor suppressor gene in cancers from different tissue origins. It is assumed that the loss of tumor suppressor gene function correlates with an aggressive tumorigenic phenotype (23). siRNA technology in combination with in vitro cell-based growth assays (such as anchorage-independent growth assay) has been recently recognized as a successful strategy for identification of new tumor suppressor genes (24). In this context, and to better understand the functional relevance of $A H R R$ as a tumor suppressor gene, we artificially suppressed its expression by siRNA technology in the lung tumor A549 and normal breast MCF10A cell lines (Supplemental Figure 3). Transfected cells were tested for a number of established hallmark traits of the tumorigenic phenotype such as growth and colony formation both in vivo and in vitro and resistance to apoptosis, migration, and angiogenic potential (25).

Silencing of AHRR enhances tumor growth in vitro and in vivo through deregulation in cell cycle control. The hallmark of all neoplastic development is deregulated cell proliferation (25). Downregulation of AHRR resulted in enhanced cell growth potential (Figure 2A). After 5 days of transfection, a difference of 4.3- and 2.6-fold in growth was observed between A549E and A549G/F, respectively. Cell cycle analysis on these cells showed that the cell number on $\mathrm{G}_{2} / \mathrm{M}$ phase of A549F/G was significantly higher than that of A549E (Figure 2 , B-D). Consistently, $G_{0} / G_{1}$ phase was significantly decreased in these cells. In addition, we determined that several prooncogenic factors were significantly elevated on A549G, including Ras, PKCa, and cyclin A, while tumor suppressor factors such as PTEN and Ku80 were downregulated (Table 2). Further strengthening these results, downregulation of AHRR enhanced the ability of A549F and A549G to form colonies on anchorage-independent clono- 

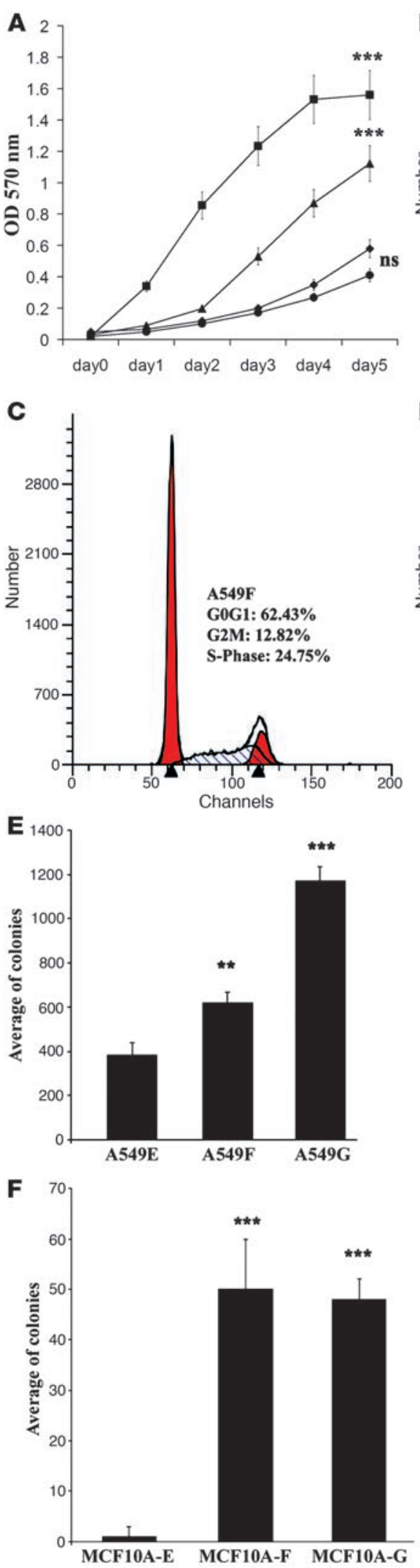
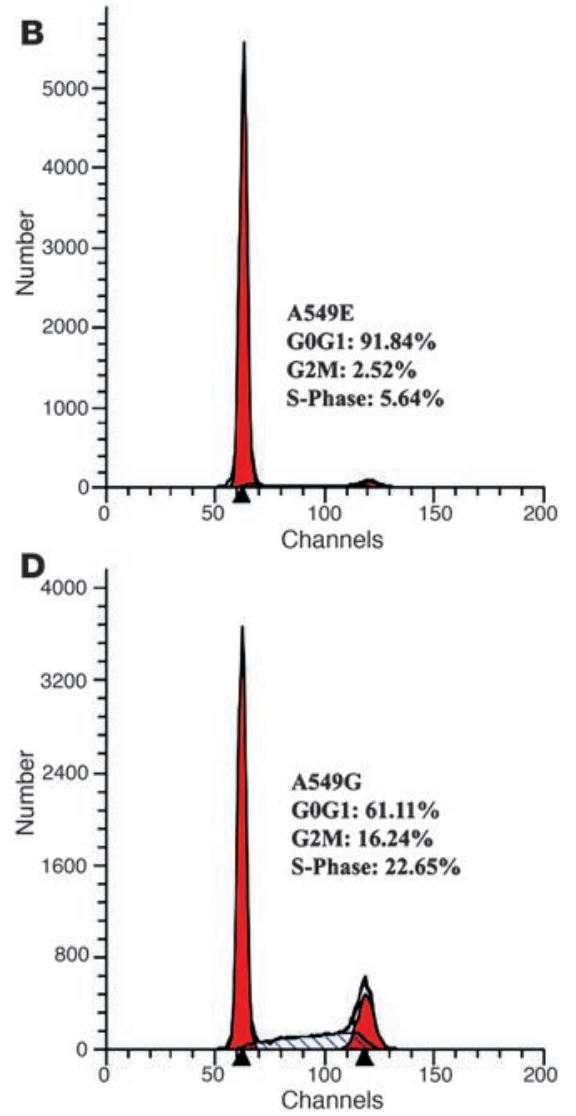

G

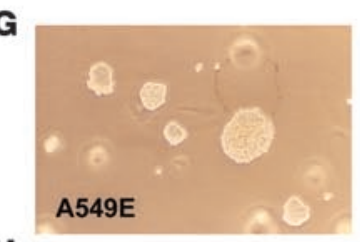

H
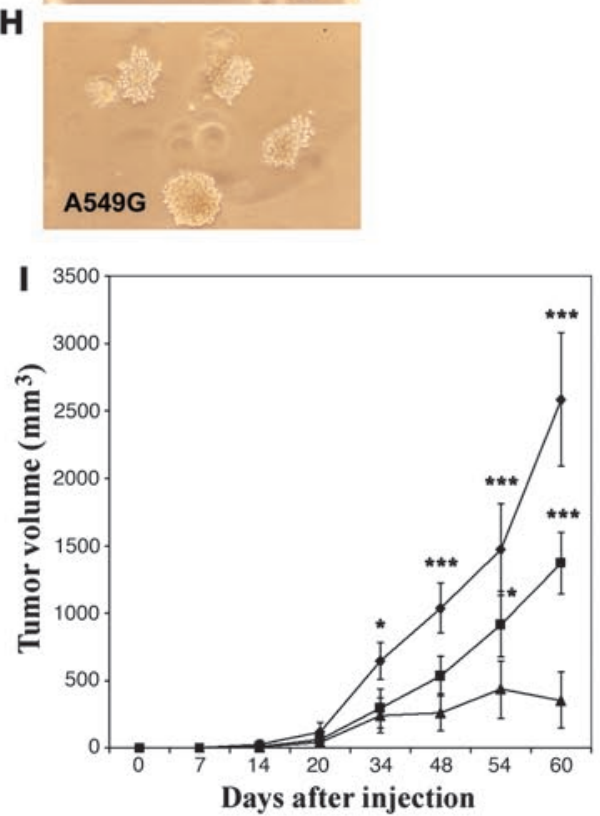

Figure 2

Effects of siRNA-induced silencing of AHRR on growth. (A) On a time-course MTT assay, A549G (squares) grew 4.3-fold and A549F (triangles) grew 2.6-fold faster than the empty nonsilenced A549 cells (circles, A549E; diamonds, A549SR). No differences were observed between A549E and A549SR. (B-D) Cells deficient in AHRR (A549F [C] and A549G [D]) showed a significant shift in the number of cells towards $\mathrm{S}$ and $\mathrm{G}_{2} / \mathrm{M}$ phases as compared with the control A549E (B). Consistently, a reduction in the number of cells in $G_{0} / G_{1}$ phase was observed in A549F/G. (E and $\mathbf{F}$ ) Artificial downregulation of $A H R R$ enhanced A549 (E) and MCF10A (F) colony formation $(60 \%$ and $300 \%$ increase in average colonies for A549F/G and A549E, respectively). MCF10A-F and MCF10A-G were able to clone in soft agar, while, as expected, MCF10A-E did not form colonies. All clonogenic assays were run in triplicate. ( $\mathbf{G}$ and H) Comparison of the morphology of the colonies formed by A549E (G) and A549G (H). A549E grew in compact spheroids with defined contours. A549G colonies showed irregular morphology and cells detached and partially separated from the core of the colony. Original magnification, $\times 20$. (I) In an in vivo experiment, A549 cells transfected with a siRNA for AHRR showed a significant increase in xenograft tumor volume 8 weeks after injection when compared with empty plasmid-transfected A549 cells (3-fold increase for A549F [squares] compared with A549E [triangles] and 7-fold increase for A549G [diamonds] compared with A549E). $n=10$ animals/group. ${ }^{*} P<0.05 ;{ }^{* *} P<0.01$; ${ }^{\star \star \star} P<0.001$ 


\section{Table 2}

Comparison of the protein expression levels between A549G and A549E

\begin{tabular}{|c|c|c|c|}
\hline Protein name & SwissProt ID & Fold change & Comments \\
\hline Vimentin & P08670 & +33.07 & Overexpression is associated with metastatic potential \\
\hline HES-1 & NF & +6.67 & Regulates Notch and potentially plays a role in tumorigenesis \\
\hline LAP2 & Q62733 & +6.13 & $\begin{array}{l}\text { May play an important role in nuclear envelope reassembly at the end of mitosis and/or } \\
\text { anchoring of the nuclear lamina and interphase chromosomes to the nuclear envelope }\end{array}$ \\
\hline TA01 & 088664 & +4.66 & Regulates MAPK pathway \\
\hline Casein kinase II a/a' & P19139 & +4.17 & Related with transformed phenotype and survival of cancer cells \\
\hline Stat6 & P42226 & +3.36 & Mediates repression of immunosurveillance \\
\hline Phosphospecific FAK & Q05397 & +3.13 & Enhances cell motility, invasion, and tumor progression \\
\hline $\mathrm{PKC} \alpha$ & P17252 & +1.8 & $\begin{array}{l}\text { Implicated in events leading to keratinocyte differentiation, epidermal tumor promotion, and } \\
\text { cutaneous inflammation }\end{array}$ \\
\hline Cyclin A & P20248 & +1.5 & Key cell cycle regulator, the expression of which is found to be elevated in a variety of tumors \\
\hline PTEN & 000633 & -1.8 & Tumor suppressor gene, the downregulation of which enhances migration \\
\hline Stat1 & A46159 & -1.9 & Mediates growth inhibitory signals and contributes to the host rejection of tumors \\
\hline MCM5 & P33992 & -2.4 & Enhances Stat1 transactivation function \\
\hline Ku80 & P13010 & -2.7 & Mediates inhibition of hepatocellular carcinoma development \\
\hline PKB & P31749 & -2.96 & Leads to downregulation of tumor suppressor gene p53 \\
\hline DAP kinase & P53355 & -3.65 & Loss of expression links suppression of apoptosis to metastasis \\
\hline E-cadherin & P12830 & -4.65 & $\begin{array}{l}\text { Loss of expression represents a key step in the acquisition of the invasive phenotype for } \\
\text { many tumors }\end{array}$ \\
\hline $\mathrm{Bcl}-\mathrm{x}$ & Q07817 & $\mathrm{BL}$ & Potent antiapoptotic factor \\
\hline Bip/GRP78 & P11021 & $\mathrm{BL}$ & Highly induced in growing tumors \\
\hline Ras & P01112 & $\mathrm{BL}$ & Oncogene that promotes cell progression \\
\hline
\end{tabular}

BL, below the detection limit in A549 and present in A549G; NF, not found in SwissProt database. Only data generated from good-quality signals with fold changes $>1.5$ were considered.

genic assays (162\% and 306\% over A549E, respectively) (Figure 2E). Of note, the enhanced clonogenic capability was accompanied by differences in the morphology of the colonies. A549E typically grew in solid spheroids with defined colony contours (Figure $2 \mathrm{G}$ ), whereas some of the colonies formed by A549F/G showed irregular contours and cells detached from the main core of the colony (Figure $2 \mathrm{H}$ ). To further explore the link between AHRR silencing and clonogenic potential, we artificially silenced $A H R R$ in the immortalized nonmalignant breast epithelial cell line MCF10A. In agreement with a previous report (26), MCF10A-E failed to form colonies in soft agar (Figure 2F). In contrast, MCF10A-F/G were able to grow in colonies displaying similar morphology to the one observed in $\mathrm{A} 549 \mathrm{~F} / \mathrm{G}$.

Overall, the data described above clearly demonstrate a link between AHRR downregulation and tumor cell growth in vitro. To further address this finding in an in vivo model of tumorigenesis, we injected A549E/F/G cells into nude mice and followed the development of xenograft tumors over time. A549F- and A549Ginduced tumors showed a 3 - and 7-fold increase in volume, when compared with tumors generated by A549E (Figure 2I). Smaller differences were found between A549E and A549F (3-fold increase). These data further suggest that downregulation of $A H R R$ is a contributing factor to enhanced tumorigenicity.

AHRR silencing protects against apoptosis and enhances angiogenic potential, migration, and invasion in tumor cells. In addition to growth deregulation and clonal expansion, resistance to apoptosis (27), enhanced angiogenic potential (28), and motility (25) lie at the heart of all tumor development. Here we show that silencing of AHRR confers resistance to apoptosis induced by overnight exposure to various proapoptotic signals (Figure 3A). Proteomics expression profile of A549G cells showed a significant elevation of the antiapoptotic fac- tor Bcl-x (Table 2), suggesting potential explanatory mechanisms. We also studied the angiogenic potential of transfected A549 cells in vivo using DIVAA. An 8-fold increase in neovascularization-related fluorescence was observed in A549G when compared with A549E (Figure 3B). Similarly, A549F exhibited higher angiogenic potential (5-fold increase) compared with A549E. Although sprouting of capillaries from quiescent vasculature on the tumor is a prerequisite for metastasis (28), enhanced motility and invasiveness are also required. The morphological alterations observed in A549F/G in clonogenic assays (Figure 2, F and G) suggest loss of cell-cell contact within the colonies and possibly higher migratory potential. Additionally, A549F/G showed increased (7- and 4.5-fold increase, respectively) migratory potential over A549E (Figure 3C). Similar results were obtained when testing the invasive potential of A549-transfected cells. Silencing of AHRR correlated with increased invasion, as observed through Matrigel staining (Figure 3C). These results are consistent with upregulation of prometastatic factors such as vimentin or phosphorylated focal adhesion kinase (FAK) and loss of E-cadherin, which is associated with loss of cell-cell interactions and enhanced invasive phenotype, in cells with artificially silenced AHRR (Table 2).

Ectopic expression of AHRR opposes the effect of siRNA for AHRR. Overexpression of AHRR was achieved in a transient fashion in A549 lung adenocarcinoma cells (Supplemental Figure 3C). AHRR was initially described as a repressor of the AHR, and our hypothesis contemplates a suppressor activity of AHRR linked to the AHR tumorigenic potential. To confirm biological activity of the overexpressed AHRR, we measured levels of the AHR-induced cancer-related gene CYP1A1. As expected, transfection of AHRinduced CYP1A1 expression and cotransfection of AHRR counteracted the effect of AHR on reducing the levels of CYP1A1 (Figure 

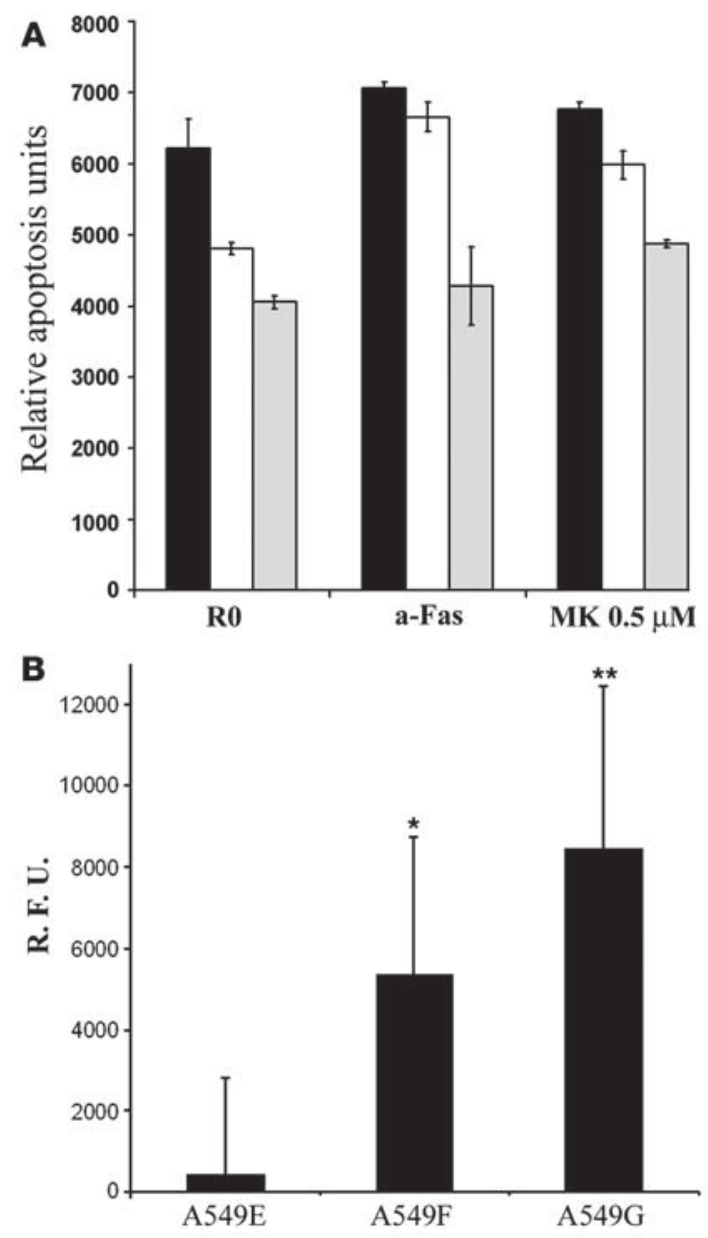

C

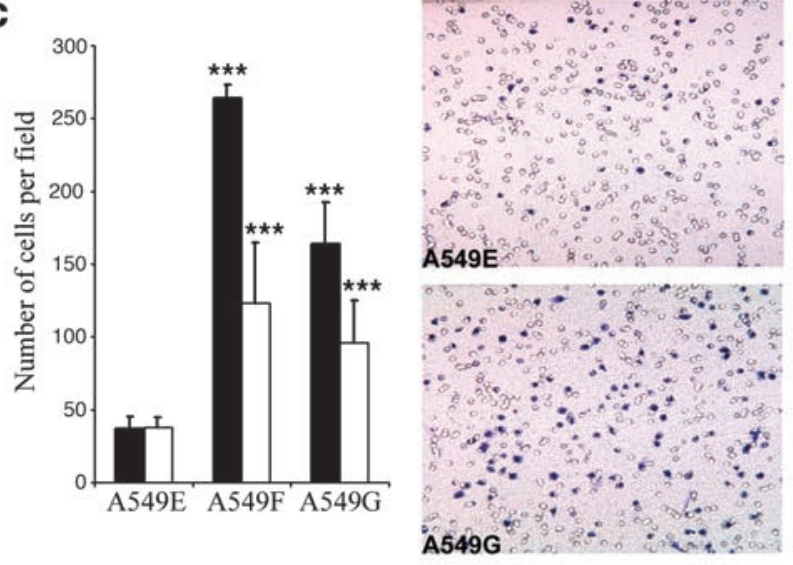

4A), therefore confirming biological activity of the overexpressed AHRR as a repressor of AHR. Interestingly, A549-AHRR showed reduced growth rate over 3 days compared with A549-empty, as assessed by Electric Cell-Substrate Impedance Sensing (Figure 4B). Consistently, AHRR transfer resulted in inhibition of anchorageindependent growth in clonogenic assays (Figure 4C). Colonies were morphologically similar and reached the same size (Figure 4B), although significantly fewer colonies were found in A549AHRR samples. Also, using a modified tube formation assay in which PAE-GFP were cocultured (in separate Matrigel compart-

\section{Figure 3}

Effects of siRNA-induced silencing of AHRR. (A) A549E (black bars), A549F (white bars), and A549G (gray bars) were incubated in serumfree media $(\mathrm{R} 0)$ or the appropriate media containing $\alpha$-Fas or MK886. In all experiments $(n=3)$, A549F/G showed enhanced resistant to proapoptotic signals when compared with A549E. (B) DIVAA analysis showed that A549F and A549G have enhanced angiogenic potential when compared with A549E, and this effect was more prominent for A549G than for A549F $(n=8)$. (C) Silencing of AHRR (A549F/G) enhances the migratory (black bars) and invasive (white bars) potential of the A549 tumor cell line $(n=6)$. Detail photos of the porous membranes used to determine migratory potential of $\mathrm{A} 549 \mathrm{E}$ and $\mathrm{A} 549 \mathrm{G}$ are also shown. Original magnification, $\times 10 .{ }^{*} P<0.05 ;{ }^{* *} P<0.01$; ${ }^{* *} P<0.001$.

ments) with transfected A549 cells (Figure 4D), we demonstrated reduced tube formation after exposure to A549-AHRR compared with cells exposed to A549-empty, showing that overexpression of $A H R R$ reduced the angiogenic potential of A549.

\section{Discussion}

Tumor formation arises as a consequence of the acquisition of unique cellular capabilities, which involve, among others, deregulation of cell proliferation, resistance to apoptosis, enhanced cell motility, augmented angiogenic potential, and anomalies in cellcell interaction and the microenvironment, resulting in invasion and metastasis (25). Over the last several years, we have learned that this process is regulated by a relatively small subset of genes that act by either enhancing (oncogenes) or diminishing (tumor suppressor genes) the final malignant outcome (29). Finding tumor suppressor genes is challenging, and although approaches based on analysis of $\mathrm{LOH}$ have been proven to be successful (29), we now know that multiple lines of evidence, including functional implications, are needed to confirm the identification of newly defined tumor suppressor genes (30). Here we provide clinical, genetic, and functional evidence supporting the hypothesis that silencing of the AHRR occurs in tumors from different tissue origins and that this mute expression results in an aggressive tumorigenic phenotype, thus suggesting that $A H R R$ plays an important role in suppressing tumor formation in humans.

In this study we demonstrate downregulation of $A H R R$ throughout all the tumor types assessed, including colon, breast, lung, stomach, cervical, and ovarian, when compared with normal tissues of the same origin. Functional inactivation of tumor suppressor genes is achieved by a combination of $\mathrm{LOH}$, hypermethylation of the gene's promoter, and mutations $(20,31)$. We have found high rates of $\mathrm{LOH}$ (together with several new polymorphisms) and hypermethylation in the promoter region of the AHRR gene in cervical, testicular, and ovarian tumors. The majority of tumors, particularly ovarian cancer and testicular germ cell tumors, exhibited only methylated alleles, which can result from $\mathrm{LOH}$ of one allele and methylation of the other or methylation of both alleles. The first mechanism may certainly account for a proportion of cases, since $5 \mathrm{p} 15 \mathrm{LOH}$ is a common event in cervical cancer and testicular germ cell tumors $(12,21,32-34)$. These data, together with the reactivation of $A H R R$ expression after exposure to demethylating agents, are consistent with Knudson's 2-hit hypothesis $(20,31)$ and indicate that $\mathrm{LOH}$ and hypermethylation constitute the main mechanism for the silencing of AHRR in tumors. Inactivation of tumor suppressor genes can represent an early event and a prerequisite for clonal expansion. In support of this idea we, have found 

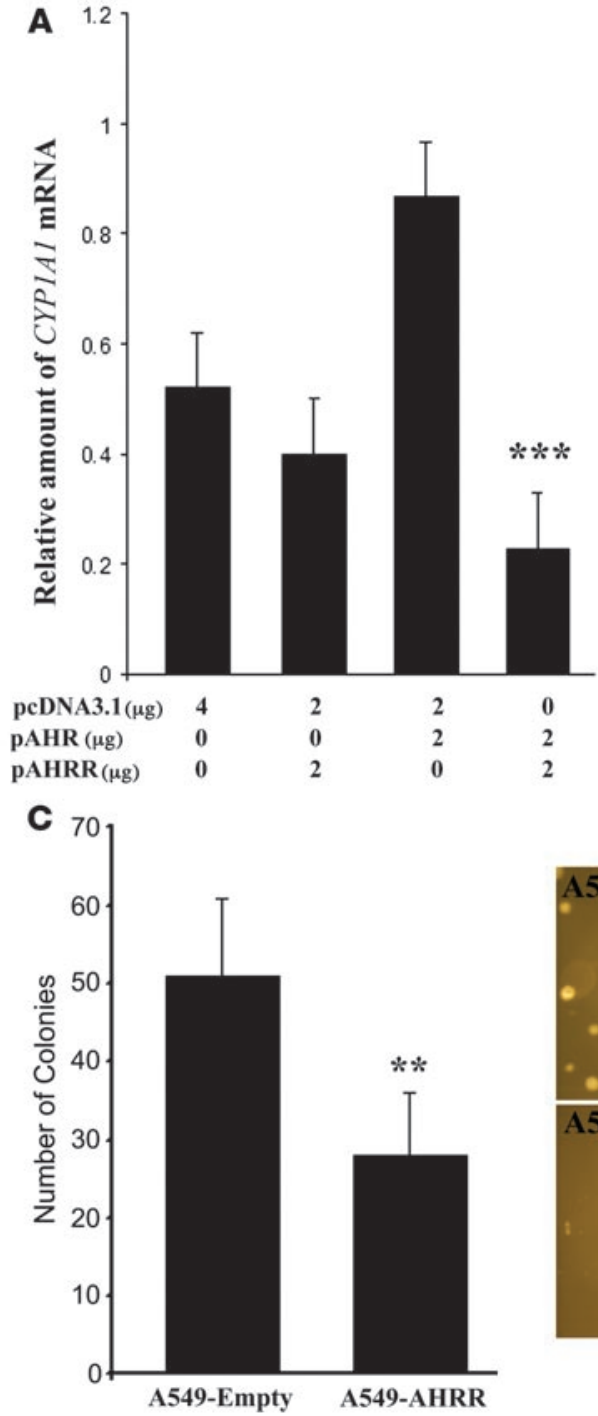

B

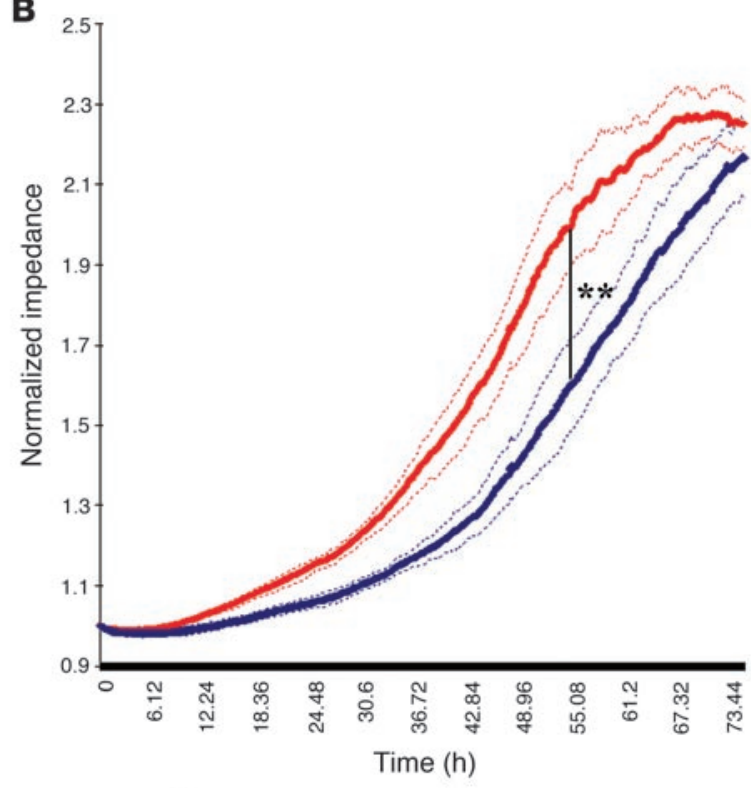

D
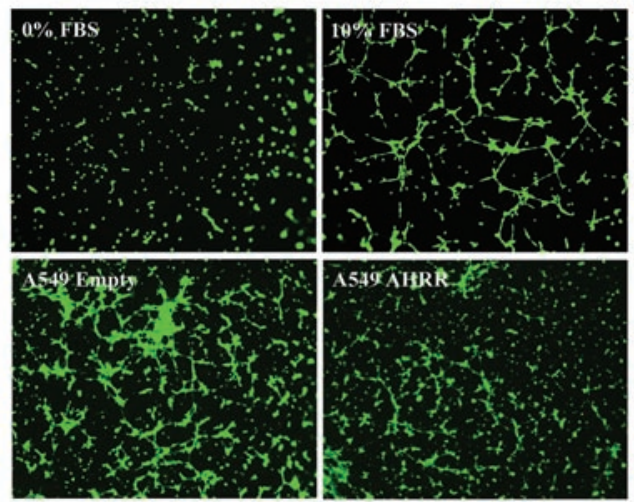

Figure 4
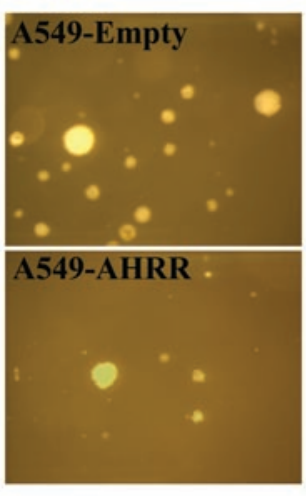

Effect of ectopic expression of AHRR in A549. (A) Overexpression of AHRR partially blocked expression of AHR-induced genes such as CYP1A1 (plasmid amounts expressed in $\mu \mathrm{g}$ ). (B) Increased levels of $A H R R$ in A549 resulted in reduced anchorage-dependent growth. The blue line represents A549-AHRR, and the red line represents A549-empty. Dotted lines denote standard deviation $(n=4)$. The maximum difference was reached 56 hours after inoculation of cells in the wells. (C) Ectopic expression of $A H R R$ resulted in reduced anchorage-independent growth (adjacent images). Original magnification, $\times 10$ (C); $\times 2$ (D). (D) Representative images of tube formation assays using cocultures of A549-empty or A549-AHRR and PAE-GFP cells. A549-empty induced tube formation of PAE-GFP cells comparable to that of the internal positive control (10\% FBS). Reduced tube formation was observed when PAE-GFP cells were cocultured with A549-AHRR. ${ }^{\star \star} P<0.01 ;{ }^{\star \star \star} P<0.001$.

a direct relationship between hypermethylation of the AHRR promoter region and tumor grade in cervical and esophageal cancer. Further supporting this idea, a small set of colon polyps (which we can consider as a naturally occurring example of premalignant lesions) showed intermediate downregulation of AHRR compared with colon tissues from healthy patients and frank colon tumors. This leads us to postulate that a reduced dosage of AHRR in the polyps, rather than its absolute absence, may contribute to cancer susceptibility in initial stages of the carcinogenic process.

Hypermethylation in the neighborhood of the start codon has been shown to suppress gene expression in tumor cells by either interfering with RNA polymerase II initiation or transcription factor binding (35). This region is therefore more likely to contain binding sequences for transcription factors relevant in AHRR regulation in tumor cells. Several regions of the promoter of the AHRR gene have been shown to be potentially relevant for the regulation of its expression $(36,37)$. We have found that the sequence contained between $-55 \mathrm{bp}$ and $-41 \mathrm{bp}$ from the start codon of the AHRR gene (which we have shown to be hypermethylated in tumors) is rich in potential binding sites for several members of the bHLH family of transcription factors, some of which are known to be upregulated in tumor cells (AHR, c-myc/MAX, and HIF-1). Upregulation of these transcription factors in cancer cells would potentially correlate with an increase in the levels of AHRR and an enhanced cancer suppressive action. However, hypermethylation of this promoter region and $\mathrm{LOH}$ prevent AHRR expression with 
A
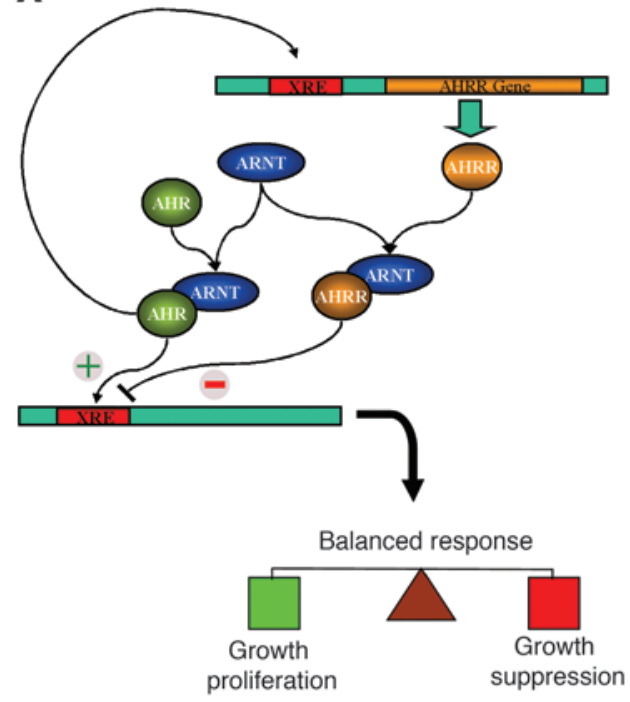

Homeostasis
B

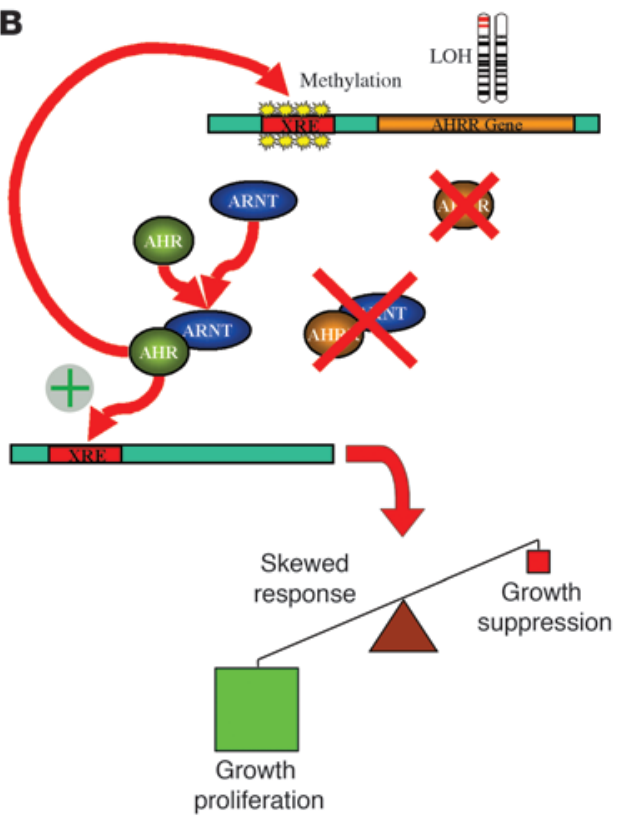

Tumorigenesis

Figure 5

Working model of the tumor suppression mechanism for $A H R R$ integrated in a gene regulation feedback loop with $A H R$. (A) In normal cells, activation of $A H R$ causes induction of $A H R R$ through XREs present in its promoter. AHRR acts as a negative regulator of $A H R$ by competing for binding to ARNT and XREs present in the promoter regulatory region of variety of genes. The balanced relationship between the positive and negative transactivation signals of $A H R$ and $A H R R$ results in cellular homeostasis. (B) In cancer cells, methylation of the AHRR promoter and $\mathrm{LOH}$ cause blockade of its expression despite the higher levels of AHR. Thus absence of AHRR eliminates competition for binding to ARNT and XREs, which results in an imbalance between positive and negative transactivation signals, thereby causing the induction of a battery of genes related to tumorigenesis and cancer progression.

concomitant loss of its repressor function and enhancement of the tumorigenic phenotype (Figure 5). Due to the significant length of the regulatory region on the $A H R R$ gene, additional studies targeting this area are guaranteed to deepen our understanding of the role that methylation plays on AHRR expression in tumor cells.

Functional evidence of the tumor suppressive nature of $A H R R$ arises from the study of the malignant phenotype in cells with artificially altered $A H R R$ expression. Independent of the etiology of different tumors, deregulated cell proliferation together with suppressed apoptosis constitute a common platform upon which all neoplastic evolution occurs. Here we demonstrate that downregulation of AHRR enhances growth potential through deregulation in cell cycle control and resistance to apoptosis (potentially through deregulation of cyclin A and Bcl-x, respectively). $A H R R$ inactivation is also linked to enhancement in anchorageindependent growth of tumor cells. Artificial upregulation of $A H R R$ results in impaired anchorage-dependent and -independent growth. In agreement with these data, a recent report shows that overexpression of $A H R R$ results in blockade of growth in the breast cancer cell line MCF-7 (18). Interestingly, partial silencing of AHRR in nontumoral MCF10A (which lack the ability of anchorage-independent growth; ref. 26) enables them to clone in soft agar, further supporting the important role of $A H R R$ as a negative regulator of clonogenicity. Recently it has been shown that immortalized mouse mammary fibroblasts lacking $A H R$ have impaired tumorigenicity in a subcutaneous mouse xenograft model (38) and that its overexpression promotes progres-
One of the essential capabilities that enhances cancer cells' tumorigenicity is their ability to migrate and become invasive. Here we show that silencing of AHRR tracks with increased motility and invasive potential in tumor cells and is accompanied by loss of E-cadherin, augmentation in vimentin, and phosphorylated FAK expression. Deregulation of these proteins has been previously related to an increase in migratory potential and a more invasive phenotype in tumors (40-42). Consistent with our results, a recent report has shown that cells lacking AHR expression show downregulation of FAK and impaired migratory capabilities (38). The increased motility and the defined proteomic profile in AHRR-deficient cells could also account for the abnormal colony morphology observed in clonogenic assays in which cells appeared to detach and migrate away from the main core of the colony. Tumor growth and metastasis rely on angiogenesis, the induction of new sprouting capillaries from quiescent vasculature (28). AHRR expression in tumor cells inversely correlates with their angiogenic potential. Tumor cells ectopically overexpressing AHRR showed lower angiogenic potential, while tumor cells in which AHRR expression was blocked showed high angiogenic potential. In summary, our data support that enhanced growth, clonal expansion, motility, and angiogenic potential, together with increased resistance to apoptotic signals, are cellular capabilities gained as a result of downregulation of $A H R R$ expression and account for the xenograft growth potential of AHRR low-expressing cells in vivo.

The clinical, genetic, and functional data presented here implicate $A H R R$ as a key regulator in the tumorigenic process whose down- 
regulation (a consequence of methylation in tumor cells) induces pleiotropic effects, leading to tumor promotion and progression. Our data are consistent with the hypothesis that $A H R R$ acts as a tumor suppressor gene in cancers from different tissue origins. The broad spectrum of signaling pathways regulated by AHRR renders this molecule an attractive biological target for developing new therapeutic intervention approaches against human cancers.

\section{Methods}

Normal tissue, tumor specimens, and cell lines. Colon specimens (normal controls and polyps) were obtained from standard colon pinch biopsies obtained during routine colonoscopy of patients without known predisposition to colon cancer and from patients with hereditary nonpolyposis colorectal cancer under protocols approved by the Internal Review Boards of both the National Cancer Institute (NCI) and the National Naval Medical Center. Lung cancer and distal normal tissue was obtained from the University of Colorado Cancer Center Lung SPORE Tissue Bank. Tumors and corresponding normal tissue were snap frozen and stored in liquid nitrogen. Total RNA from pairs of individual human tumor and adjacent normal tissues (colon, lung, stomach, and breast) were obtained from Ambion. DNA isolated from 10 normal cervical smears and a total of 66 tumors from cervix uteri ( 9 cell lines and 57 primary tumors) were utilized as described previously (43). All primary cervical cancers were squamous cell carcinoma of stages Ib to IV. Cervical cancer cell lines (HT-3, ME-180, HeLa, MS751, C-4I, C-33A, CaSki, SW756, and SiHa) were obtained from the ATCC. DNA obtained from 4 normal testes and 79 testicular germ cell tumors were used as previously described (44). All tumors (at least $60 \%$ tumor cellularity) were obtained after appropriate informed consent and approval of the protocols were obtained from the NIH IACUC. Total RNA from normal cervixes was purchased from 3 different sources (Ambion, Stratagene, and BioChain). DNA isolated from 2 normal ovarian cell lines (immortalized ovarian surface epithelium -IOSE 80 and IOSE 120; ref. 45 ) and 14 ovarian carcinoma cell lines (A2780, AD10, OVCAR429, A224, CP70, OVT2[OF], CAOV3, 222, A547, A364, OVCAR3, UCI101, SKOV03, and UCI107) were also included in this study (46). All the ovarian cell lines were cultured as previously described (47). The bronchoalveolar carcinoma cell line A549, small lung cancer H417, and carcinoid H720 were obtained from ATCC. MCF10A was kindly provided by David Salomon (NCI) and maintained as previously described (26). The porcine endothelial cell PAE was obtained from Lena Claesson-Welsh (The Rudbeck Laboratory, Uppsala University, Uppsala, Sweden) through MTA agreement and subcultured as previously described (48).

$R N A$ reverse transcription and real-time $P C R$. Reverse transcription was performed using the SuperScript First-Strand Synthesis system (Invitrogen). PCR was performed using the ABI Prism 7900 Sequence Detection System (Applied Biosystems). Amplification was performed using $10 \mu \mathrm{M}$ each of the following sense and antisense primers: AHRR sense, 5'-CTTAATGGCTTTGCTCTGGTCG-3'; AHRR antisense, 5'-TGCATTACATCCGTCTGATGGA-3'; 18S rRNA sense, 5'-ATGCTCTTAGCTGAGTGTCCCG-3'; 18S rRNA antisense, $5^{\prime}$-ATTCCTAGCTGCGGTATCCAGG-3' and SYBR Green Master Mix (Applied Biosystems).

$D N A$. The standard amplification program was according to the following cycle scheme: initial denaturation of the samples at $50^{\circ} \mathrm{C}$ for $2 \mathrm{~min}$, $95^{\circ} \mathrm{C}$ for $10 \mathrm{~min}, 40$ cycles of $95^{\circ} \mathrm{C}$ for $15 \mathrm{~s}, 60^{\circ} \mathrm{C}$ for $60 \mathrm{~s}$. Fluorescence was measured in every cycle, and a defined single peak in the melting curve was obtained for all amplicons, thus confirming the specificity of the amplification. The final mRNA levels of the genes studied were normalized according to the $18 \mathrm{~S}$ rRNA concentration of each sample.

Mutational analysis. Primer sets covering coding exons 2-11, and $5^{\prime}$ of exon 11 of $A H R R$ gene were designed to amplify genomic DNA up to 240 bp (Supplemental Table 1). Single-strand conformation polymorphism (SSCP) analysis was performed on PCR products generated from 30 cervical cancers in the presence of $\alpha\left[{ }^{32} \mathrm{P}\right] \mathrm{dCTP}$ and running $6 \%$ nondenaturing polyacrylamide gels containing $10 \%$ glycerol. Purified PCR products were sequenced to identify mutations.

Promoter methylation analysis by methylation-specific PCR. A CPG island (1,222 bp) spanning intron 1/exon 2/intron 2 of the AHRR gene was identified using GrailEXP Grail Experimental Gene Discovery Suite (http://grail. lsd.ornl.gov/grailexp/). Two sets of primers for amplification of methylated and unmethylated DNA were designed by standard methods and were as follows: AHRR-M-F3, 5'-GTACGTGTATTTTTTCGGCG-3'; AHRR-M-R3, 5'-CCGATAACTCCTCGATACGA-3'; AHRR-U-F3, 5'-GTATGTGTATTTTTTTGGTGG-3'; AHRR-U-R3, 5'-CCCAATAACTCCTCAATACA-3' (-208 to $27 \mathrm{bp}$ ); and AHRR-M-F2, 5'-TTCGTCGTTTTCGTTTTTGTC-3'; AHRR-M-R2, 5'-CGAACGAACCGAAACTAAACTC-3'; AHRR-U-F2, 5'-GGTGGTTTTGTTTGTGGAGTTT-3'; AHRR-U-R2, 5'-AAAACTCATCCCTACACCCTCA-3' (-333 to -178 bp). Genomic DNA was treated with sodium bisulfite as previously described (43). Placental DNA treated in vitro with SssI methyltransferase (New England Biolabs) and normal lymphocyte DNA treated similarly with sodium bisulfite were used as controls for methylated and unmethylated templates, respectively. PCR products obtained from standard reaction were run on $2 \%$ agarose gels and visualized after ethidium bromide staining.

5-Aza-2' deoxycytidine and trichostatin treatment and analysis of gene expression. Tumor cell lines (cervical: C-41, CaSKi, C-33A, HT-3, siHA, SW756, MS751m, ME-180, HeLa; testicular: CL2102EP, 2CL-21218A; and lung: A549, H720, H417) were treated with demethylating agent 5-Aza-2' deoxycytidine (Sigma-Aldrich) for 5 days at a concentration of $5 \mu \mathrm{M}$, HDAC-inhibiting agent trichostatin A (Sigma-Aldrich) at a final concentration of $250 \mathrm{nM}$ for the last 24 hours, or a combination of both. Total RNA isolated from treated and untreated cell lines and the total RNA and polyA+ RNA from normal cervix obtained from commercial sources were reverse transcribed using random primers and the ProSTAR firststrand RT-PCR kit (Stratagene).

Analysis of transcription factor binding sites in the promoter region of the AHRR gene. The 155 -bp region corresponding to -333 bp to $27 \mathrm{bp}$ from the start codon of the AHRR gene was searched for transcription factor binding sites using MathInspector software (49) (Genomatix Software GmbH). Only sequences with core similarity of 1 , matrix similarity greater than 0.9 , and optimized matrix threshold greater than 0.8 were considered.

Construction of expression plasmids and generation of transfectants. The mammalian expression vector pSuper.neo (OligoEngine) was used for expression of an AHRR-specific siRNA in A549 and MCF10A cells. Two gene-specific inserts (5'-GAGCTTCTTCCAAGTCGTG-3' and 5'-GGCTGCTGTTGGAGTCTCTT-3') were cloned into the pSUPER.neo backbone, and the final plasmids were referred to as pSuper.neo-F and pSuper.neo-G, respectively. A control vector containing no insert (empty vector, referred to as pSuper.neo-E) or a plasmid containing a scramble sequence (referred to as pSuper.neo-sr) or wild-type untransfected cells served as nonsilencing controls. To assess the appropriateness of the nonsilencing controls, equal levels of AHRR mRNA were confirmed in A549 transfected with pSuper. neo-sr (A549SR), untransfected cells (A549WT), and A549 transfected with the empty vector (A549E) (Supplemental Figure 1A). Similar growth and migratory rates among A549E, A549SR, and A549WT were also observed (Supplemental Figure 1, B and C). The complete open reading frame of the human AHRR gene was amplified by PCR, cloned into the pcDNA 3.1 TOPO TA mammalian expression vector (Invitrogen), and transiently transfected into A549 cells (A549-AHRR). Control vector (pcDNA3.1) containing no insert was used to generate negative control cells (A549-empty). The open reading frame of GFP was cloned into the pcDNA3.1 TOPO TA 
backbone (pcDNA3.1-GFP). All vectors were sequenced in the forward and reverse directions to verify the insertion of the AHRR and GFP sequences and the lack of insert in the control plasmids. A549 and MCF10A cells were transfected with plasmids pSuper.neo-E, pSuper.neo-F, or pSuper. neo-G using FuGENE6 (Invitrogen) and exposed to the appropriate media containing $800 \mu \mathrm{g} / \mathrm{ml}$ geneticin (Invitrogen). A549 was transiently transfected with PAHRR and pcDNA3.1 using the AMAXA nucleofector system. Expression of AHRR in both siRNA stable transfectants and transient overexpressors was assessed by real-time PCR (Supplemental Figure 3). PAE cells were transiently transfected with pcDNA3.1-GFP (PAE-GFP). Selection of expressing cells was achieved by flow cytometry cell sorting using FACScan and CellQuest software (Becton Dickinson).

Growth assays. Proliferation of cells stably transfected with siRNA for $A H R R$ or the empty vector was assessed by MTT assay. The dye and solubilization solutions (Promega Proliferation Assay) were added every day for 5 days to separate 96-well plates, and absorbance was measured at $570 \mathrm{~nm}$ with a Spectra Rainbow (Tecan) plate reader. Growth potential of A549-AHRR was assessed by Electric Cell-Substrate Impedance Sensing (ECIS Model 9600; Applied Biophysics) (50). A549-AHRR and A549-empty cells were seeded in $8 \mathrm{~W} 10 \mathrm{E}+$ plates in RPMI supplemented with $10 \%$ FBS (RPMI-10). Measurements were performed for 4 days at $15 \mathrm{kHz}$.

Cell cycle analysis. For DNA content analysis, $3 \times 10^{6}$ cells (A549E, A549F, and A549G) were fixed, permeabilized in $70 \%$ ethanol, and washed twice in PBS ( $\mathrm{pH}$ 7.4). Cells were then resuspended in $1 \mathrm{ml}$ of PBS containing $50 \mu \mathrm{g}$ propidium iodide (Sigma-Aldrich) and 1,000 units of DNAse-free RNase (Sigma-Aldrich) and incubated for $30 \mathrm{~min}$ at $37^{\circ} \mathrm{C}$. The samples were run on a FACScan using CellQuest software and analyzed using the Sync Wizard option of MODFIT LT 2.0 (Verity Software House Inc.).

Soft agar clonogenic assay. The anchorage-independent growth of A549E, A549F, A549G, A549-empty, and A549-AHRR cells was examined by soft agar clonogenic assay. Briefly, 5,000 cells were resuspended in $1.5 \mathrm{ml}$ of the culture media containing $10 \% \mathrm{FBS}$ and $0.3 \%$ agarose and plated in 6-well plates with $1.5 \mathrm{ml}$ of pre-solidified culture media in $0.5 \%$ agar containing $10 \% \mathrm{FBS}$. Plates were incubated at $37^{\circ} \mathrm{C}$ for 4 weeks, and colonies larger than $0.1 \mathrm{~mm}$ in diameter were counted. The same procedure was followed for MCF10A-E, MCF10A-F, and MCF10A-G seeding 20,000 cells per well.

Xenografts. A549 cells transfected with the AHRR siRNA plasmids or the empty vector were injected into the flanks of athymic (nude) mice $\left(1 \times 10^{7}\right.$ cells/mouse). The mice (10 animals/cell line) were checked daily for tumor formation by palpation, and tumor volume was estimated by measuring its size in 3 dimensions twice a week. This experiment was conducted in a blind fashion under animal protocol approved by the Animal Care and Usage Committee of NCI-Frederick Cancer Research Center.

Apoptosis assay. Cells were suspended in RPMI-10, seeded in 96-well plates, and incubated overnight. Then the plates were washed with RPMI media and exposed to: serum-free RPMI, RPMI-10 and $\alpha$-Fas $(5 \mu \mathrm{g} / \mathrm{ml}$; MBL International Co.), and RPMI-10 and $0.5 \mu \mathrm{M}$ of MK886 (SigmaAldrich). After overnight incubation, early apoptosis was determined as the production of caspase-3/7 products using the Apo-ONE Homogenous Caspase-3/7 Assay (Promega).

1. Burbach, K.M., Poland, A., and Bradfield, C.A. 1992. Cloning of the Ah-receptor cDNA reveals a distinctive ligand-activated transcription factor. Proc. Natl. Acad. Sci. U. S. A. 89:8185-8189.

2. Wang, G.L., Jiang, B.H., Rue, E.A., and Semenza, G.L. 1995. Hypoxia-inducible factor 1 is a basichelix-loop-helix-PAS heterodimer regulated by cellular O2 tension. Proc. Natl. Acad. Sci. U. S. A. 92:5510-5514.

3. Hoffman, E.C., et al. 1991. Cloning of a factor required for activity of the Ah (dioxin) receptor. Science. 252:954-958.
Migration assays. Chemotaxis was assayed in 8- $\mu \mathrm{m}$ pore, 96 -well ChemoTx plates (Neuroprobe). Cells $\left(5 \times 10^{5}\right)$ were placed in the upper chambers and the lower wells were filled with RPMI-10. After a 4-hour migration period at $37^{\circ} \mathrm{C}$, nonmigrating cells were wiped off the top surface of the membrane. Then the membranes were fixed and stained with Hema3 (Biochemical Sciences Inc.), and the cells trapped in the pores of the membrane were counted. Eight repeats were performed per sample.

Tube formation assays. The same number of A549-empty or A549-AHRR cells were seeded in 96-well plates. After the cells completely attached, the cells were washed 3 times with serum-free RPMI. Then $50 \mu$ l of basement membrane extract (Trevigen) was laid down in each well. PAE-GFP cells $(15,000)$ were then added on top of the gelled BME, and images were acquired with a fluorescent microscope after 3.5 hours.

Directed in vivo angiogenesis assay. Quantitation of angiogenesis was done using directed in vivo angiogenesis assay (DIVAA) as previously described (51). Briefly, 10-mm-long surgical grade silicone tubes with only 1 open end (angioreactors) were filled with $20 \mu \mathrm{l}$ of Matrigel alone or Matrigel containing 10,000 cells. After the Matrigel solidified, the angioreactors were implanted into the dorsal flanks of anesthetized athymic nude mice (NCI colony). After 11 days, the mice were injected i.v. with $25 \mathrm{mg} / \mathrm{ml} \mathrm{FITC-dex-}$ $\operatorname{tran}(100 \mu \mathrm{l} /$ mouse; Sigma-Aldrich) $10 \mathrm{~min}$ before removing angioreactors. Quantitation of neovascularization in the angioreactors was determined as the amount of fluorescence trapped in the implants and was measured in a SpectraFluor microplate reader (Tecan). This protocol was approved by the NIH IACUC.

Proteomic analysis. A549G and A549E cells ( $10^{6}$ cells per assay) were suspended in boiling lysis buffer (10 mM Tris- $\mathrm{HCl}$ [pH 7.4], $1 \mathrm{mM}$ sodium orthovanadate, $1 \%$ SDS) and homogenized by sonication. The protein content of each lysate was quantified by the bicinchoninic acid assay (Pierce Biotechnology) and subsequently processed by the PowerBlot facility (Becton Dickinson) to measure the expression level of 280 different signaltransducing proteins related to cell cycle regulation and proteins susceptible of phosphorylation. The experiment was performed in triplicate.

Statistics. Comparisons between groups were made using the 2-tailed Student's $t$ test and the Mann-Whitney $U$ test. Plotted data were expressed as mean \pm SD. ${ }^{*} P<0.05,{ }^{* *} P<0.01$, and ${ }^{* *} P<0.001$ are significance values used in the figures.

\section{Acknowledgments}

The study was supported by the University of Colorado Cancer Center Lung_SPORE grant 5P50 CA 058187-13 and by NCI Intramural funding project Z01SC000173.

Received for publication August 10, 2006, and accepted in revised form October 29, 2007.

Address correspondence to: Enrique Zudaire, NCI Angiogenesis Core Facility, NCI, NIH, Advanced Technology Center, Suite 115, Bethesda, Maryland 20892-4605, USA. Phone: (301) 496-8050; Fax: (301) 435-8036; E-mail: zudairee@mail.nih.gov.
4. Mimura, J., Ema, M., Sogawa, K., and Fujii-Kuriyama, Y. 1999. Identification of a novel mechanism of regulation of $\mathrm{Ah}$ (dioxin) receptor function. Genes Dev. 13:20-25.

5. Reyes, H., Reisz-Porszasz, S., and Hankinson, O. 1992. Identification of the Ah receptor nuclear translocator protein (Arnt) as a component of the DNA binding form of the Ah receptor. Science. 256:1193-1195.

6. Denison, M.S., and Nagy, S.R. 2003. Activation of the aryl hydrocarbon receptor by structurally diverse exogenous and endogenous chemicals.
Annu. Rev. Pharmacol. Toxicol. 43:309-334.

7. Kasai, A., et al. 2006. High levels of dioxin-like potential in cigarette smoke evidenced by in vitro and in vivo biosensing. Cancer Res. 66:7143-7150.

8. Moennikes, O., et al. 2004. A constitutively active dioxin/aryl hydrocarbon receptor promotes hepatocarcinogenesis in mice. Cancer Res. 64:4707-4710.

9. Andersson, P., et al. 2002. A constitutively active dioxin/aryl hydrocarbon receptor induces stomach tumors. Proc. Natl. Acad. Sci. U. S. A. 99:9990-9995.

10. Koliopanos, A., et al. 2002. Increased arylhydrocarbon receptor expression offers a potential 
therapeutic target for pancreatic cancer. Oncogene. 21:6059-6070.

11. Shimada, T., et al. 2002. Arylhydrocarbon receptordependent induction of liver and lung cytochromes P450 1A1, 1A2, and 1B1 by polycyclic aromatic hydrocarbons and polychlorinated biphenyls in genetically engineered C57BL/6J mice. Carcinogenesis. 23:1199-1207.

12. Mitra, A.B., et al. 1995. Genetic alterations at $5 \mathrm{p} 15$ : a potential marker for progression of precancerous lesions of the uterine cervix. J. Natl. Cancer Inst. 87:742-745.

13. Xu, S.F., Peng, Z.H., Li, D.P., Qiu, G.Q., and Zhang, F. 2003. Refinement of heterozygosity loss on chromosome $5 \mathrm{p} 15$ in sporadic colorectal cancer. World J. Gastroenterol. 9:1713-1718.

14. Wang, V.W., Bell, D.A., Berkowitz, R.S., and Mok, S.C. 2001. Whole genome amplification and highthroughput allelotyping identified five distinct deletion regions on chromosomes 5 and 6 in microdissected early-stage ovarian tumors. Cancer Res. 61:4169-4174.

15. Bohm, M., Kleine-Besten, R., and Wieland, I. 2000. Loss of heterozygosity analysis on chromosome $5 \mathrm{p}$ defines $5 \mathrm{p} 13-12$ as the critical region involved in tumor progression of bladder carcinomas. Int. J. Cancer. 89:194-197.

16. Peralta, R.C., et al. 1998. Distinct regions of frequent loss of heterozygosity of chromosome $5 \mathrm{p}$ and $5 \mathrm{q}$ in human esophageal cancer. Int. J. Cancer. 78:600-605.

17. Wieland, I., et al. 1996. Allelic deletion mapping on chromosome 5 in human carcinomas. Oncogene. 12:97-102.

18. Kanno, Y., Takane, Y., Izawa, T., Nakahama, T., and Inouye, Y. 2006. The inhibitory effect of aryl hydrocarbon receptor repressor (AhRR) on the growth of human breast cancer MCF-7 cells. Biol. Pharm. Bull. 29:1254-1257.

19. Kim, S.H., et al. 2007. Association between susceptibility to advanced stage endometriosis and the genetic polymorphisms of aryl hydrocarbon receptor repressor and glutathione-S-transferase T1 genes. Hum. Reprod. 22:1866-1870.

20. Knudson, A.G. 2001. Two genetic hits (more or less) to cancer. Nat. Rev. Cancer. 1:157-162.

21. Arias-Pulido, H., Narayan, G., Vargas, H., Mansukhani, M., and Murty, V.V. 2002. Mapping common deleted regions on $5 \mathrm{p} 15$ in cervical carcinoma and their occurrence in precancerous lesions. Mol.
Cancer. 1:3.

22. Smiraglia, D.J., et al. 2002. Distinct epigenetic phenotypes in seminomatous and nonseminomatous testicular germ cell tumors. Oncogene. 21:3909-3916.

23. Donehower, L.A., et al. 1992. Mice deficient for p53 are developmentally normal but susceptible to spontaneous tumours. Nature. 356:215-221.

24. Downward, J. 2005. RNA interference libraries prove their worth in hunt for tumor suppressor genes. Cell. 121:813-815.

25. Hanahan, D., and Weinberg, R.A. 2000. The hallmarks of cancer. Cell. 100:57-70.

26. Soule, H.D., et al. 1990. Isolation and characterization of a spontaneously immortalized human breast epithelial cell line, MCF-10. Cancer Res. 50:6075-6086.

27. Evan, G.I., and Vousden, K.H. 2001. Proliferation, cell cycle and apoptosis in cancer. Nature. 411:342-348.

28. Hanahan, D., and Folkman, J. 1996. Patterns and emerging mechanisms of the angiogenic switch during tumorigenesis. Cell. 86:353-364.

29. Stanbridge, E.J. 1990. Identifying tumor suppressor genes in human colorectal cancer. Science. 247:12-13.

30. White, R.L. 1998. Tumor suppressing pathways. Cell. 92:591-592.

31. Jones, P.A., and Laird, P.W. 1999. Cancer epigenetics comes of age. Nat. Genet. 21:163-167.

32. Murty, V.V., et al. 1994. Allelic loss and somatic differentiation in human male germ cell tumors. Oncogene. 9:2245-2251.

33. Ku, W.H., et al. 1997. Genomic deletion and p53 inactivation in cervical carcinoma. Int. J. Cancer. 72:270-276.

34. Luft, F., Gebert, J., Schneider, A., Melsheimer, P. and von Knebel Doeberitz, M. 1999. Frequent allelic imbalance of tumor suppressor gene loci in cervical dysplasia. Int. J. Gynecol. Pathol. 18:374-380.

35. Tate, P.H., and Bird, A.P. 1993. Effects of DNA methylation on DNA-binding proteins and gene expression. Curr. Opin. Genet. Dev. 3:226-231.

36. Baba, T., et al. 2001. Structure and expression of the Ah receptor repressor gene. J. Biol. Chem. 276:33101-33110.

37. Haarmann-Stemmann, T., et al. 2007. Analysis of the transcriptional regulation and molecular function of the aryl hydrocarbon receptor repressor in human cell lines. Drug Metab. Dispos. 35:2262-2269.

38. Mulero-Navarro, S., et al. 2005. Immortalized mouse mammary fibroblasts lacking dioxin receptor have impaired tumorigenicity in a subcutaneous mouse xenograft model. J. Biol. Chem. 280:28731-28741.

39. Elferink, C.J. 2003. Aryl hydrocarbon receptormediated cell cycle control. Prog. Cell Cycle Res. 5:261-267.

40. Hsia, D.A., et al. 2003. Differential regulation of cell motility and invasion by FAK. J. Cell Biol. 160:753-767.

41. Cavallaro, U., and Christofori, G. 2004. Cell adhesion and signalling by cadherins and Ig-CAMs in cancer. Nat. Rev. Cancer. 4:118-132.

42. Hu, L., et al. 2004. Association of Vimentin overexpression and hepatocellular carcinoma metastasis. Oncogene. 23:298-302.

43. Narayan, G., et al. 2003. Frequent promoter methylation of CDH1, DAPK, RARB, and HIC1 genes in carcinoma of cervix uteri: its relationship to clinical outcome. Mol. Cancer. 2:24.

44. Koul, S., et al. 2002. Characteristic promoter hypermethylation signatures in male germ cell tumors. Mol. Cancer. 1:8.

45. Maines-Bandiera, S.L., Kruk, P.A., and Auersperg, N. 1992. Simian virus 40-transformed human ovarian surface epithelial cells escape normal growth controls but retain morphogenetic responses to extracellular matrix. Am. J. Obstet. Gynecol. 167:729-735.

46. Manzano, R.G., et al. 2002. CL100 expression is down-regulated in advanced epithelial ovarian cancer and its re-expression decreases its malignant potential. Oncogene. 21:4435-4447.

47. Hendricks, D.T., Taylor, R., Reed, M., and Birrer, M.J. 1997. FHIT gene expression in human ovarian, endometrial, and cervical cancer cell lines. Cancer Res. 57:2112-2115.

48. Waltenberger, J., et al. 1994. Different signal transduction properties of KDR and Flt1, two receptors for vascular endothelial growth factor. J. Biol. Chem. 269:26988-26995.

49. Quandt, K., Frech, K., Karas, H., Wingender, E., and Werner, T. 1995. MatInd and MatInspector: new fast and versatile tools for detection of consensus matches in nucleotide sequence data. Nucleic Acids Res. 23:4878-4884.

50. Giaever, I., and Keese, C.R. 1993. A morphological biosensor for mammalian cells. Nature. 366:591-592.

51. Guedez, L., et al. 2003. Quantitative assessment of angiogenic responses by the directed in vivo angiogenesis assay. Am. J. Pathol. 162:1431-1439. 